\title{
Renalase and lupus nephritis: disease activity and histopathological classification
}

\author{
Marwa Y. Mahgoub ${ }^{a}$, Ali I. Foda ${ }^{a}$, Ahmed Y. Elshambaky ${ }^{a}$, \\ Amira MN Abdelrahman ${ }^{\mathrm{b}}$, Sarah N. Nasif ${ }^{\mathrm{b}}$, Rania G. El Sayed ${ }^{\mathrm{c}}$
}

\begin{abstract}
Departments of ${ }^{\mathrm{a}}$ Rheumatology, Rehabilitation and Physical Medicine, ${ }^{b}$ Clinical Pathology, Benha University, Benha, 'Department of Rheumatology, Rehabilitation and Physical Medicine, Tokh Central Hospital, Tokh, Egypt

Correspondence to Marwa Y. Mahgoub, MD Department of Rheumatology, Rehabilitation and Physical Medicine, Benha University, Benha, 13511, Egypt. Tel: 0133232679 ; e-mail: marwayahiamlm@gmail.com
\end{abstract}

Received 8 May 2018

Accepted 15 July 2018

Egyptian Rheumatology \& Rehabilitation 2018, 45:175-181

\begin{abstract}
Aim
To measure the level of serum renalase and to clarify its relation to lupus nephritis (LN) activity and histopathological classification.

\section{Patients and methods}

This study was carried out on 40 patients with systemic lupus erythematosus (SLE), diagnosed according to systemic lupus international collaborating clinics classification criteria (SLICC) criteria, and 20 healthy controls. They were 20 patients without nephritis and 20 patients with LN (17 active and three inactive $\mathrm{LN})$. Venous blood samples were taken from all participants for complete blood count, erythrocyte sedimentation rate, kidney function, anti-double-stranded DNA, C3, C4, and renalase level. The serum renalase levels were determined by enzyme-linked immunosorbent assay. Assessments of protein in 24-h urine collection and protein/creatinine $(\mathrm{P} / \mathrm{C})$ ratio were done. Renal biopsies were obtained from patients with LN, with staging and activity and chronicity indices assessment. SLE disease activity was measured by Systemic Lupus Erythematosus Disease Activity Index, and LN activity was estimated by renal Systemic Lupus Erythematosus Disease Activity Index.

Results

Renalase levels were higher in patients with LN than both patients with SLE without LN and control group. The serum renalase levels of patients with LN were positively correlated with $\mathrm{P} / \mathrm{C}$ ratio, 24-h proteinuria and $\mathrm{C} 3$, but negatively correlated with Systemic Lupus Erythematosus Disease Activity Index. For patients with active LN, there was no significant correlation between their serum renalase levels and the indicators of renal activity, including erythrocyte sedimentation rate, proteinuria, $\mathrm{P} / \mathrm{C}$ ratio, anti-double-stranded DNA, C3, C4, and activity index of renal biopsy. The median of renalase as a marker for diagnosis of $L N$ was 134.65 , with a cutoff value of $100 \mu \mathrm{g} / \mathrm{ml}$. Conclusion
\end{abstract}

Serum renalase may be involved in LN pathogenesis but was not a good predictor for either LN activity or various stages of LN histopathology.

\author{
Keywords: \\ lupus nephritis, renalase, histopathogenesisxx \\ Egypt Rheumatol Rehabil 45:175-181 \\ (0) 2018 Egyptian Society for Rheumatology and Rehabilitation \\ 1110-161X
}

\section{Introduction}

Systemic lupus erythematosus (SLE) is a chronic autoimmune disorder that can affect virtually any organ of the body. Clinical features in individual patients can be quite variable, ranging from mild joint and skin involvement to severe life-threatening internal organ disease. The pathogenesis of SLE, which involves the various facets of the immune system, is complex and perplexing [1].

The kidney is the signature organ affected in SLE, and almost all studies of prognosis have identified lupus nephritis (LN) as a significant predictor of poor outcome [2].

LN has varying clinical presentations and consequences. It is diagnosed by the presence of urine protein/creatinine $(\mathrm{P} / \mathrm{C}$; or $24-\mathrm{h}$ urine protein) representing $500 \mathrm{mg}$ of protein $/ 24 \mathrm{~h}$ or cell casts, and more definitely by biopsy [3]. Usually, an elevated erythrocyte sedimentation rate (ESR) and antidouble-stranded DNA (anti-dsDNA) and low C3 and $\mathrm{C} 4$ levels are associated with active nephritis, especially focal proliferative and diffuse proliferative LN. Clinically relevant LN is associated with a $30 \%$ decrease in creatinine clearance, proteinuria of greater than $1000 \mathrm{mg} / \mathrm{d}$, and renal biopsy findings indicating active LN [4]. Kidney involvement is a great predictor of poor outcome in SLE, with $5-10 \%$ progression to

This is an open access journal, and articles are distributed under the terms of the Creative Commons Attribution-NonCommercial-ShareAlike 4.0 License, which allows others to remix, tweak, and build upon the work non-commercially, as long as appropriate credit is given and the new creations are licensed under the identical terms. 
end-stage renal disease (ESRD) despite immunosuppressive therapy [5].

The principal goal of therapy in LN is to normalize renal function or, at least, to prevent the progressive loss of renal function. So early detection of $\mathrm{LN}$ or its activity is considered an essential step for proper treatment and better prognosis.

Renalase (amine oxidase), which is capable of metabolizing catecholamines, is mostly secreted by the kidney into the blood. Recently, reduced plasma renalase concentration was detected in patients with ESRD [6]. Up to our knowledge, there was only one published data about the potential role of renalase in $\mathrm{LN}$ pathogenesis and activity [7]. Therefore, this study was conducted to study the possibility of correlation of the serum renalase levels to the histopathogenesis and the activity of $\mathrm{LN}$.

\section{Patients and methods}

This study was carried out on 40 patients with SLE, diagnosed according to systemic lupus international collaborating clinics classification criteria (SLICC) criteria [8], and 20 healthy controls. They were recruited from the inpatients and the outpatients' clinic of Rheumatology, Rehabilitation and Physical Medicine Department, Benha University Hospitals. All participants were females, and their ages ranging between 20 and 49 years. The patient group included 20 patients without nephritis and 20 patients with LN, with 17 active LN and three inactive LN, grouped according to renal Systemic Lupus Erythematosus Disease Activity Index (rSLEDAI). The control group consists of 20 apparently healthy individuals with matched age and sex. All patients and controls provided an informed consent before participation. This work was approved by the ethical committee of faculty of medicine, Benha University.

Clinical histories and blood samples were collected from all patients and controls, and also renal biopsies were obtained from patients with $\mathrm{LN}$ on the same day of blood sampling. SLE disease activity was assessed according to the SLEDAI score to mild (score, 0-10), moderate (score, 11-20), severe (score, 21-45), and very severe (score $>45$ ), with rSLEDAI consisted of four kidney-related items of the total SLEDAI: hematuria, pyuria, proteinuria, and urinary casts/high power field (HPF), and ranges from 0 (inactive renal disease) to a maximum score of 16 [9].

Venous blood samples were obtained from all participants, and the following parameters were measured: complete blood count, serum creatinine, creatinine clearance, antinuclear antibody by immunofluorescence technique, anti-dsDNA antibody, complement $\mathrm{C} 3$ and $\mathrm{C} 4, \mathrm{C}$-reactive protein, and ESR. The 24-h urine and spot urine sample was collected to estimate urinary protein excretion. Serum renalase was determined by blood coagulation at room temperature for 10-20 min, and then centrifugation for $20 \mathrm{~min}$ at a speed of 2000-3000 rpm for separation of the serum, which was then kept at $-20^{\circ} \mathrm{C}$ until used. Serum renalase levels were carried out using a sandwich monoclonal enzymelinked immunosorbent assay kit for renalase in human urine and serum (EIAab Science Inc., Wuhan, China).

Renal biopsies of patients with LN enrolled in this study were obtained by ultrasound-guided procedure and evaluated using the International Society of Nephrology/Renal Pathology Society classification [10].

\section{Results}

Our participants were grouped to group $\otimes$, which included 20 patients with SLE without renal manifestation, and their ages ranged from 20 to 49 years (mean $\pm \mathrm{SD}, 28.90 \pm 6.55$ ); group $\otimes \mathrm{I}$, which included 20 patients with SLE with renal manifestation, and their ages ranged from 25 to 44 years $(m e a n \pm S D, 29.60 \pm 4.92)$, which was subdivided to subgroup IIa that included 17 (85\%) patients with LN showing active disease and subgroup IIb that included three (15\%) patients with LN showing inactive disease; and finally, group III, the control group, and their ages ranged from 20 to 48 years (mean \pm SD, 29.90 \pm 7.11 ).

Focusing on our aim, renalase levels were higher in patients with LN than both patients with SLE without LN and control group (Table 1). The cutoff value of

Table 1 Serum renalase level comparison among the studied groups

\begin{tabular}{|c|c|c|c|}
\hline $\begin{array}{l}\text { Serum } \\
\text { renalase } \\
(\mathrm{ng} / \mathrm{ml})\end{array}$ & $\begin{array}{c}\text { Group I SLE } \\
\text { without LN } \\
(N=20)\end{array}$ & $\begin{array}{c}\text { Group II SLE } \\
\text { with LN } \\
(N=20)\end{array}$ & $\begin{array}{l}\text { Group III } \\
\text { control } \\
(N=20)\end{array}$ \\
\hline $\begin{array}{l}\text { Interquartile } \\
\text { range }\end{array}$ & $54.23-122.6$ & 72.63-892.98 & $54.28-153.78$ \\
\hline $\begin{array}{l}\text { Median } \\
\mathrm{Kw}_{\chi^{2}}\end{array}$ & 69 & $\begin{array}{l}134.65 \\
4.541\end{array}$ & 63.3 \\
\hline$P$ value & & $0.014^{*}$ & \\
\hline & $\begin{array}{l}\text { Group I and } \\
\text { group II }\end{array}$ & $\begin{array}{l}\text { Group I and } \\
\text { group III }\end{array}$ & $\begin{array}{l}\text { Group II and } \\
\text { group III }\end{array}$ \\
\hline$z_{\mathrm{MW}}$ & $0.012^{*}$ & 0.714 & $0.032^{*}$ \\
\hline
\end{tabular}




\begin{tabular}{lcccccc}
\hline & Cutoff & Sensitivity (\%) & Specificity (\%) & PPV (\%) & NPV (\%) & Accuracy (\%) \\
\hline Serum renalase & 100 & 72 & 89 & 78 & 85 & 81 \\
\hline
\end{tabular}

NPV, negative predictive value of a test; PPV, positive predictive value of a test.

serum levels of renalase was $100 \mathrm{ng} / \mathrm{ml}$ with sensitivity $72 \%$ and specificity $89 \%$ of the test. The positive predictive value of the test is $78 \%$ and the negative predictive value of the test is $85 \%$. The accuracy of the test is $81 \%$ (Table 2 and Fig. 1).

We reported that serum renalase levels of patients with LN were statistically positively correlated with $\mathrm{P} /$ $\mathrm{C}$ ratio, 24-h proteinuria and $\mathrm{C} 3$, but negatively correlated with SLEDAI. However, patients with SLE without LN had no statistically significant correlation between their serum renalase and all the clinical and laboratory parameters as shown in Table 3.

For patients with active LN, there was no significant correlation between their serum renalase levels and the indicators of renal activity including ESR, proteinuria, $\mathrm{P} / \mathrm{C}$ ratio, anti-dsDNA, $\mathrm{C} 3, \mathrm{C} 4$, and activity index of renal biopsy (Table 4). The median of renalase as a marker for diagnosis of $\mathrm{LN}$ was 134.65 with a cutoff value of $100 \mu \mathrm{g} / \mathrm{ml}$.

A renal biopsy from each patient with $\mathrm{LN}$ had been obtained on the same day of blood sampling. International Society of Nephrology/Renal Pathology Society classification system was used for grading LN [11].

A total of 20 patients had evidence of LN. Four (20\%) patients had LN grade II, 10 (50\%) patients had LN grade III, four (20\%) patients had LN grade IV-G, and two (10\%) patients had LN grade IV-S.

Regarding serum renalase levels, there was no statistically significant difference between the stages of renal biopsy $(P<0.05)$ (Fig. 2).

\section{Statistical analysis}

Statistical presentation and analysis of the present study was conducted, using the mean, SD and $\chi^{2}$ test by statistical package for the social sciences, version 20. The Student's $t$ test is used to compare the variables between two groups when necessary. Analysis of variance was done by analysis of variance tests $(f)$. The comparison of all categorical variables such as frequency or percentage (\%) was performed using the $\chi^{2}$ test. The correlation between two variables was determined through linear correlation coefficient $(r)$. The receiver operating characteristic curve was performed by plotting sensitivity and specificity of serum renalase values according to Youden's index. The results were expressed as $P$ value, where less than 0.05 was considered statistically significant.

\section{Discussion}

SLE is a chronic autoimmune inflammatory disease that targets the kidneys, being pathologically evident in $\sim 90 \%$ and clinically in $\sim 50 \%$ of patients. $\mathrm{LN}$ is a foremost risk factor for overall morbidity and mortality in SLE, and even with potent antiinflammatory and immunosuppressive therapies, it still ends in chronic kidney disease (CKD) or ESRD for many patients [12]. So, an early diagnosis of LN has an imperative clinical implication in administrative treatments of patients with SLE [13].

Antibodies to dsDNA and the reduction of complements $\mathrm{C} 3$ and $\mathrm{C} 4$, which are considered indicators for renal affection and activity, were also found in patients without $\mathrm{LN}$ and patients with clinically inactive SLE with a relatively high percentage [14]. Such a lack of specificity led to search for other reliable biomarkers for identifying patients with SLE with active nephritis [15].

Recently renalase (monoamine oxidase) was implicated in the pathogenesis of $\mathrm{LN}$ and its flare; therefore, our study aimed at evaluation of the serum level of renalase in patients with SLE with and without LN.

This control-case study was carried out on 40 patients with SLE, where 50\% had LN and $100 \%$ were female, and their ages ranged between 20 and 50 years. Overall, $85 \%$ of the patients with $\mathrm{LN}$ with active disease belonged to II, III, and IV grades.

Serum renalase was elevated in patients with $\mathrm{LN}$ than nonrenal patients and normal group. On the contrary, there was no statistically significant difference in its level between patients with active $\mathrm{LN}$ and those with inactive $\mathrm{LN}$.

The previous studies showed that SLE was more predominated in female with a ratio of $9: 1$ (female : male). In this study, $100 \%$ of the patients diagnosed as 
ROC Curve

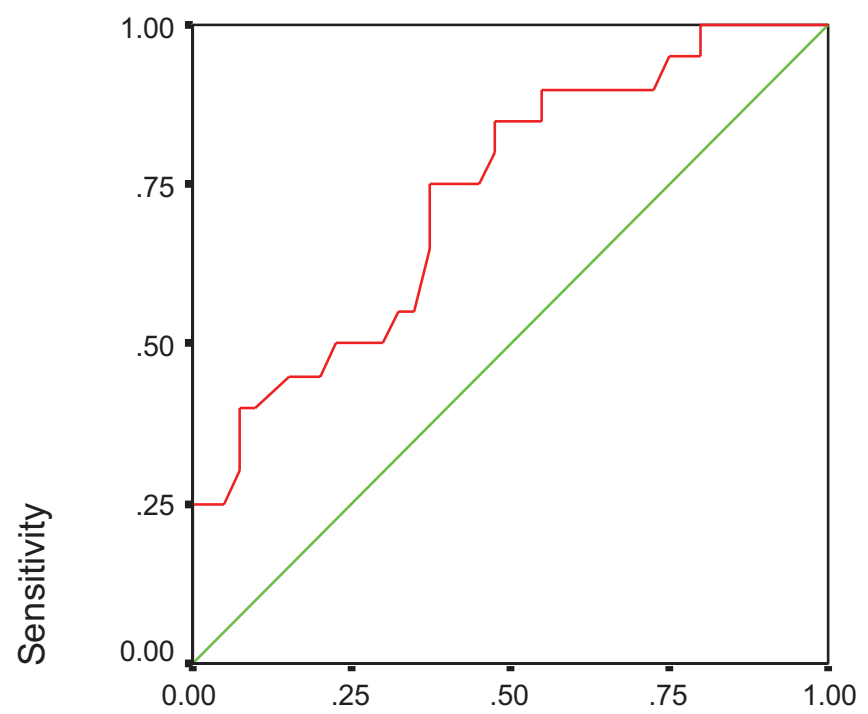

\section{1 - Specificity}

Diagonal segments are produced by ties.

A

ROC curve: Receiver operating characteristic curve.

S Renalase

B

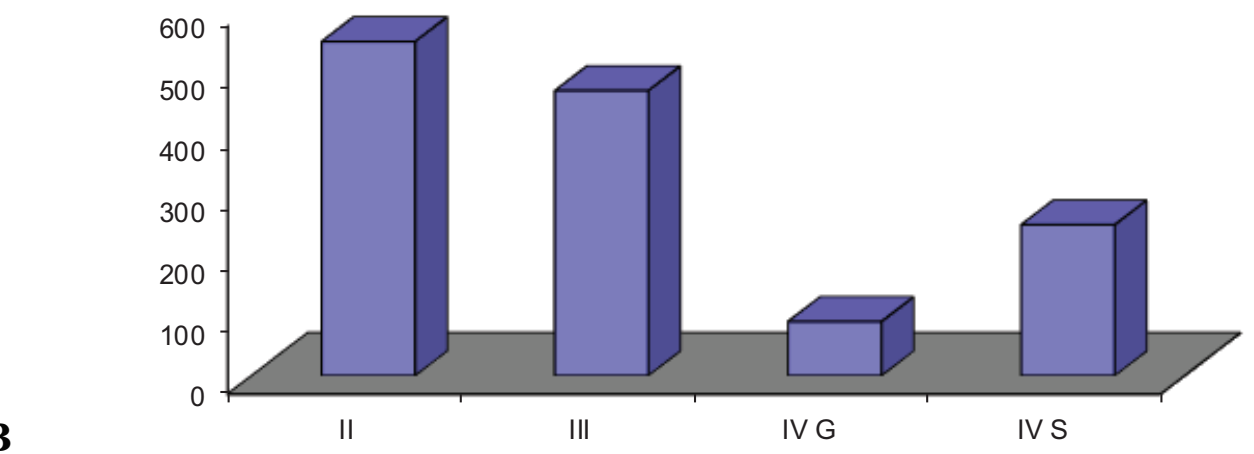

Cutoff curve of serum renalase. ROC curve, receiver operating characteristic curve.

having SLE were female. This difference may be caused by the small sample number in our study. Our patients' ages ranged between 20 and 50 years old, which is in agreement with the same age range in the patient sample obtained by Somers et al. [16].

Our results showed that 20\% had LN grade II, 50\% had LN grade III and 30\% had LN grade IV. The higher frequency of grades III and IV LN in this study might be owing to late presentation and the significant association between symptoms and signs with these grades at presentation. Our percentages were close to those of Somers et al. [16], which reported $14 \%$ class I, $22 \%$ class II, $10 \%$, class III, $35 \%$ class IV, and $20 \%$ class $\mathrm{V}$ of their studied patients.

In our current study, we found that the level of renalase was significantly higher in patients with LN compared with patients without LN and healthy controls. Moreover, in the correlation studies, we demonstrated a positive correlation between serum renalase and proteinuria, $\mathrm{P} / \mathrm{C}$ ratio and complement 3 and a negative correlation between it and SLEDAI score, which suggests the relation of renalase to the pathogenesis of $\mathrm{LN}$. The receiver operating 
Table 3 Correlation between serum renalase level and some clinical and laboratory findings between group I and group II

\begin{tabular}{|c|c|c|c|c|}
\hline & \multicolumn{4}{|c|}{ Serum renalase } \\
\hline & \multicolumn{2}{|c|}{$\begin{array}{l}\text { Group I SLE } \\
\text { without LN } \\
(N=20)\end{array}$} & \multicolumn{2}{|c|}{$\begin{array}{c}\text { Group II SLE } \\
\text { with LN }(N=20)\end{array}$} \\
\hline & $R$ & $P$ & $r$ & $P$ \\
\hline Age & -0.096 & 0.687 & -0.408 & 0.074 \\
\hline Duration & -0.074 & 0.757 & 0.488 & $0.029^{*}$ \\
\hline RBCs & -0.017 & 0.942 & 0.562 & $0.010^{*}$ \\
\hline WBCs & 0.166 & 0.484 & -0.659 & $0.002^{*}$ \\
\hline PLT & -0.352 & 0.128 & 0.793 & $0.001^{*}$ \\
\hline $\mathrm{Hb}$ & 0.002 & 0.994 & -0.256 & 0.275 \\
\hline ESR & -0.066 & 0.782 & 0.113 & 0.635 \\
\hline CRP & 0.089 & 0.709 & -0.363 & 0.055 \\
\hline Proteinuria & -0.152 & 0.522 & 0.624 & $0.004^{*}$ \\
\hline $\mathrm{P} / \mathrm{C}$ ratio & -0.090 & 0.704 & 0.726 & $0.001^{*}$ \\
\hline Creatinine clearance & -0.160 & 0.500 & -0.028 & 0.905 \\
\hline Anti-dsDNA & 0.192 & 0.419 & -0.226 & 0.338 \\
\hline ANA & 0.193 & 0.416 & -0.144 & 0.546 \\
\hline $\mathrm{C} 3$ & -0.097 & 0.683 & 0.462 & $0.040^{*}$ \\
\hline C4 & -0.095 & 0.690 & 0.289 & 0.217 \\
\hline SLEDAI & -0.299 & 0.200 & -0.466 & $0.038^{*}$ \\
\hline
\end{tabular}

ANA, antinuclear antibody; anti-dsDNA, antibodies to doublestranded deoxyribonucleic acid; C3, complement 3 level; C4, complement 4 level; CRP, C-reactive protein; ESR, erythrocyte sedimentation rate; $\mathrm{Hb}$, hemoglobin; LN, lupus nephritis; $\mathrm{P} / \mathrm{C}$ ratio, protein-to-creatinine ratio; PLT, platelet blood test; $r$, Pearson's correlation; RBCs, red blood cells; SLE, systemic lupus

erythematosus; SLEDAI, systemic lupus erythematosis disease activity index (maximum score $=105$ ); WBCs, white blood cells. $P>0.05$, significant. $P=0.001$, high significant. $P<0.05$, nonsignificant. *Significant.

characteristic curve also showed that serum renalase could be a good predictor for $\mathrm{LN}$. The results obtained by Qi et al. [8] support our findings as they reported that the level of renalase was significantly higher in patients with LN compared with healthy controls, especially in patients with proliferative LN.

On the contrary, we found that there was no significant relation between renalase level and the activity of $\mathrm{LN}$, as our data for patients with LN with active renal disease established no significant correlation between their serum renalase levels and the indicators of renal activity, including $\mathrm{ESR}$, proteinuria, $\mathrm{P} / \mathrm{C}$ ratio, antidsDNA, C3, C4, and activity index of renal biopsy.

Contrary to our data, the results by Qi et al. [8] revealed higher renalase levels in patients with active LN compared with patients with inactive $\mathrm{LN}$, especially in proliferative grade. They proved their findings by descending serum renalase levels following immunosuppressive therapy along with the anti-dsDNA antibodies, C3, and SLEDAI score. Furthermore, renalase expression was upregulated in the glomeruli of proliferative LN patients, suggesting that renalase expression and signaling may play a role in the pathogenesis of active LN.
Table 4 Correlation between serum renalase and some clinical, laboratory findings, and renal biopsy in subgroup lla

\begin{tabular}{lcc}
\hline & \multicolumn{2}{c}{ Serum renalase } \\
\cline { 2 - 3 } & \multicolumn{2}{c}{ Subgroup Ila $(N=17)$} \\
\cline { 2 - 3 } & $r$ & $P$ \\
\hline Age & -0.298 & 0.246 \\
Ruration & 0.516 & $0.034^{*}$ \\
WBCs & 0.520 & $0.032^{*}$ \\
PLT & -0.751 & $0.001^{*}$ \\
Hb & 0.891 & $0.001^{*}$ \\
ESR & -0.333 & 0.192 \\
CRP & 0.256 & 0.321 \\
Proteinuria & -0.473 & 0.055 \\
P/C ratio & 0.142 & 0.586 \\
Creatinine clearance & 0.182 & 0.485 \\
Anti-dsDNA & 0.095 & 0.716 \\
ANA & -0.126 & 0.631 \\
C3 & 0.151 & 0.562 \\
C4 & 0.310 & 0.226 \\
rSLEDAl & -0.142 & 0.587 \\
Activity index & -0.438 & 0.079 \\
Chronicity index & -0.298 & 0.246 \\
\hline ANA, antincear ant & 0.365 & 0.149 \\
\hline
\end{tabular}

ANA, antinuclear antibody; anti-dsDNA, antibodies to doublestranded deoxyribonucleic acid; C3, complement 3 level; C4 complement 4 level; CRP, C-reactive protein; ESR, erythrocyte sedimentation rate; $\mathrm{Hb}$, hemoglobin; $\mathrm{P} / \mathrm{C}$ ratio, protein-tocreatinine ratio; PLT, platelet blood test; $r$, Pearson's correlation; RBCs, red blood cells; rSLEDAI, renal systemic lupus erythematosis disease activity index (maximum score $=16$ ); WBCs, white blood cells. $P>0.05$, significant. $P=0.001$, high significant. $P<0.05$, nonsignificant. *Significant.

Our findings may be supported by the fact that LN pathogenesis takes place in the glomeruli and the main source of renalase secretion from the kidney is the proximal tubules. Lee et al. [17] confirmed the selective expression of renalase in proximal tubular cells.

We also reported that all our patients had normal renal functions represented in creatinine clearance, serum creatinine, and blood urea, with no significant relation between renalase levels. On the contrary, Malyszko et al. [18] found a relation of renalase levels to kidney function tests, as they observed that in patients with estimated glomerular filtration rate over $60 \mathrm{ml} / \mathrm{min}$, renalase was significantly lower than in patients with estimated glomerular filtration rate below $60 \mathrm{ml} / \mathrm{min}$. In addition, renalase was related in the univariate analysis to kidney function, age, time after transplantation, and markers of endothelial dysfunction. They observed that renalase levels were predicted by kidney function. It results from the fact that as kidney function deteriorates, endothelial damage increases, which is reflected by the rise in thrombomodulin, cytokines, and renalase. 


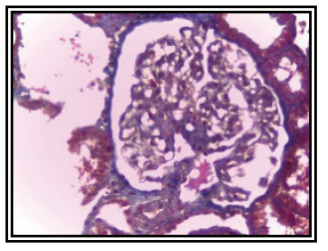

Lupus nephritis class III ISN/RPS Showing glomeruli with focal glomerulosclerosis (MT X400).

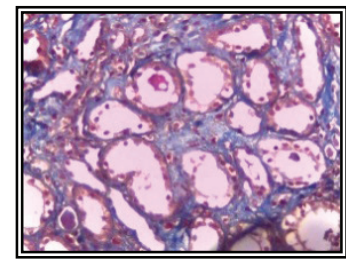

Lupus nephritis class III ISN/RPS Showing mild tubular fibrosis (MT X400

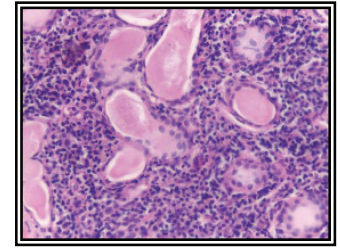

Lupus nephritis class IVG ISN/R Showing glomerulosclerosis (PAS
X400).

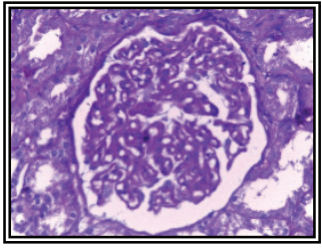

Lupus nephritis class IVs ISN/RPS Showing glomeruli with wireloop (PASs400).

Comparison between various stages of renal biopsy regarding serum renalase levels.

Another finding was documented by many previous studies that renalase level decreased in the CRD and ESRD, suggesting that renal blood flow may affect renalase production, with reflection on their blood pressure as renalase was accused in metabolizing catecholamines and resulting in hypertension in those patients $[19,7,20]$.

However, West and Marnett [21] reported differing results and explained that the significant increase in renalase levels detected in CKD and ESRD, possible, is primarily a reflection of accumulated renalase breakdown products. Moreover, it suggested that the increase level is owing to the existence of extrarenal sites for renalase secretion.

In our current study, we could not prove the relation between serum renalase levels and CKD and ESRD, and this may be owing to the small sample number of patients with inactive $\mathrm{LN}$ (three patients) in our study, being unsuitable for statistical analysis.

Regarding hypertension affected by renalase levels, Wang et al. [22] and Schlaich et al. [23] in their studies reported that decreased serum renalase level led to increase in blood pressure in their patients. Moreover, studies in animal models by $\mathrm{Xu}$ et al. [7], Wu et al. [20], Desir et al. [24], and Fedchenko et al. [25] support this finding. However, Zbroch et al. [26] reported no association between serum renalase and blood pressure in hemodialysis or peritoneal dialysis patients. We unfortunately could not relate renalase levels to hypertension in our patients for the same obstacle of having a small number of patients having hypertension (four patients).

Our study's limitations were as follows: the small sample number of patients, as they were recruited from one area, Benha University Hospitals, which also led to devoid of our study of male patients; the numbers of patients with inactive renal disease and hypertensive patients were small, which made us unable to obtain the statistical relation between them and the renalase levels; and finally, we did not scope on the effect of the immunosuppressive therapies on renalase levels in patients with renal disease. Therefore, the findings of this study need to be confirmed in a larger cohort of patients with LN and should include various ethnic groups. Our conclusion is that serum renalase may be involved in LN pathogenesis but is not a good predictor for either LN activity or various stages of LN histopathology.

\section{Financial support and sponsorship} Nil.

\section{Conflicts of interest}

There are no conflicts of interest..

\section{References}

1 Abdou MMS, Effat DA, Mansour LA, Abd El Baky NM, Abdul Salam MM. Urinary lipoxin A4 as a biomarker for systemic lupus erythematosus. Egypt Rheumatol Rehabil 2015; 42:55-61

2 Lahita RG, Tsokos G, Buyon JP, Koike T. Systemic lupus erythematosus. 5th ed. New York: Academic Press; 2010.

3 Birmingham DJ, Rovin BH, Shidham G, Nagaraja HN, Zou X, Bissell M, et al. Spot urine protein/creatinine ratios are unreliable estimates of $24 \mathrm{~h}$ proteinuria in most systemic lupus erythematosus nephritis flares. $\mathrm{J}$ Kid Int 2007; 72:865-870.

4 Hill GS, Delahousse M, Nochy D, Tomkiewicz E, Rémy P, Mignon F, et al. A new morphologic index for the evaluation of renal biopsies in lupus nephritis. J Kid Int 2000; 58: 1160-1173.

5 Fadda SH, Abd Elazeem MI, Mohammed RA, Hasan HM. Significance of antibodies to ribosomal $\mathrm{P}$ proteins in lupus nephritis patients and their relation to disease activity: clinical and laboratory study. Egypt Rheumatol Rehabil 2017; 44:130-138.

6 Dooley MA. Clinical and laboratory features of lupus nephritis. In: Wallace DJ, Hahn BH, editors. Dubois' lupus erythematosus. 7th ed. Philadelphia, PA: Lippincott Williams \& Wilkins 2007. 1112-1130

7 Xu J, Li G, Wang P, Velazquez H, Yao X, Li Y, et al. Renalase is a novel, soluble monoamine oxidase that regulates cardiac function and blood pressure. J Clin Invest 2005; 115:1275-1280.

8 Qi C, Wang L, Zhang M, Shao X, Chang X, Fan Z, et al. Serum renalase levels correlate with disease activity in lupus nephritis. PLoS One 2015; 10: e0139627.

9 Petri M, Orbai AM, Alarcón GS, Gordon C, Merrill JT, Fortin PR, et al. Derivation and validation of the Systemic Lupus International Collaborating Clinics classification criteria for systemic lupus erythematosus. J Arthritis Rheum 2012; 64:2677-2686.

10 Bombardier C, Gladman DD, Urowitz MB, Caron D, Chang CH. Derivation of the SLEDAI. A disease activity index for lupus patients. The Committee on Prognosis Studies in SLE. J Arthritis Rheum 1992; 35:630-640. 
11 Weening JJ, D'Agati VD, Schwartz MM, Seshan SV, Alpers CE, Appel GB et al. The classification of glomerulonephritis in systemic lupus erythematosus revisited. J Am Soc Nephrol 2004; 15:241-250.

12 Almaani S, Meara A, Rovin BH. Update on lupus nephritis. Clin J Am Soc Nephrol. 2017; 12:825-835. doi: 10.2215/CJN.05780616. Epub 2016 Nov.

13 Xue J, Yang J, Yang L, Zhou S, Ji C, Wang X, et al. Dickkopf-1 is a biomarker for systemic lupus erythematosus and active lupus nephritis. J Immunol Res 2017; 2017:6861575.

14 Mollnes TE, Haga HJ, Brun JG, Nielsen EW, Sjoholm A, Sturfeldt G, et al. Complement activation in patients with systemic lupus erythematosus without nephritis. Rheumatology (Ox-ford) 1999; 38:933-940.

15 Marto N, Bertolaccini ML, Calabuig E, Hughes GRV, Khamashta MA. AntiC1q antibodies in nephritis: correlation between titres and renal disease activity and positive predictive value in systemic lupus erythematosus. Ann Rheum Dis 2005; 64:444-448.

16 Somers EC, Marder W, Cagnoli P, Lewis EE, DeGuire P, Gordon C, et al. Population-based incidence and prevalence of systemic lupus erythematosus: the Michigan Lupus Epidemiology and Surveillance program. J Arthritis Rheum 2014; 66:369-378.

17 Lee HT, Kim JY, Kim M, Wang P, Tang L, Baroni S, et al. Renalase protects against ischemic AKI. J Am Soc Nephrol 2013; 24:445-455

18 Malyszko J, Zbroch E, Malyszko JS, Koc-Zorawska E, Mysliwiec M. Renalase, a novel regulator of blood pressure, is predicted by kidney function in renal transplant recipients. Transplant Proc 2011; 43:3004-3007.

19 Quelhas-Santos J, Sampaio-Maia B, Simões-Silva L, Serrão P, FernandesCerqueira C, Soares-Silva I, et al. Sodium-dependent modulation of systemic and urinary renalase expression and activity in the rat remnant kidney. J Hypertens 2013; 31:543-552.

20 Wu Y, Xu J, Velazquez H, Wang P, Li G, Liu D, et al. Renalase deficiency aggravates ischemic myocardial damage. J Kidney Int 2011; 79:853-860.

21 West JD, Marnett LJ. Alterations in gene expression induced by the lipid peroxidation product, 4-hydroxy-2-nonenal. Chem Res Toxicol 2005; 18:1642-1653.

22 Wang L, Velazquez H, Moeckel G, Chang J, Ham A, Lee HT, et al Renalase prevents $\mathrm{AKI}$ independent of amine oxidase activity. J Am Soc Nephrol 2014; 25:1226-1235.

23 Schlaich M, Socratous F, Eikelis N, Chopra R, Lambert G, Hennebry S. Renalase plasma levels are associated with systolic blood pressure in patients with resistant hypertension. J Hypertens 2010 28:e437.

24 Desir GV, Tang L, Wang P, Li G, Sampaio Maia B, Quelhas-Santos J, et al. Renalase lowers ambulatory blood pressure by metabolizing circulating catecholamines. J Am Heart Assoc 2012; 1:e002634.

25 Fedchenko V, Globa A, Buneeva O, Medvedev A. Renalase mRNA levels in the brain, heart, and kidneys of spontaneously hypertensive rats with moderate and high hypertension. Med Sci Monit Basic Res 2013; 19:267-270.

26 Zbroch E, Malyszko J, Malyszko JS, Koc-Zorawska E, Mysliwiec M. Renalase, a novel enzyme involved in blood pressure regulation, is related to kidney function but not to blood pressure in hemodialysis patients. Kidney Blood Press Res 2012; 35:395-399. 